\title{
THERAPEUTIC PLASMAPHERESIS IN A COMPLEX TREATMENT OF PATIENTS WITH CHRONIC HEPATITIS
}

D0I: 10.36740/WLek202007126

\author{
Vladislav V. Lyubchak', Viktoriia M. Plaksa', Ihor M. Pelo ${ }^{2}$, Michael P. Kovalishyn', Viktor P. Lyubchak', \\ Vladimir V. Horokh ${ }^{3}$, Tetyana Iu. Lisovenko ${ }^{4}$, Viktoriia V. Ilyina' ${ }^{1}$, Liliya M. Khomenko' \\ 1 SUMY STATE UNIVERSITY, SUMY, UKRAINE \\ ${ }^{2}$ BOGOMOLETS NATIONAL MEDICAL UNIVERSITY, KYIV, UKRAINE \\ ${ }^{3}$ SUMY REGIONAL CLINICAL HOSPITAL, SUMY, UKRAINE \\ ${ }^{4}$ SUMY CITY CLINICAL HOSPITAL N0.5, SUMY, UKRAINE
}

\begin{abstract}
The aim: To determine the pathogenetic expediency, efficiency and the place of therapeutic plasmapheresis in a complex treatment of patients with chronic hepatitis. Materials and methods: It was carried out the analysis of case histories of 77 patients. In the course of treatment, the patients were diagnosed with chronic toxic hepatitis (K.71). Diagnosis was exposed in accordance with the official documentation introduced by the Gastroenterological department of Sumy Regional Clinical Hospital CH"SRCH", Sumy Regional Infectious Diseases Clinical Hospital named after Krasovytsky ZY and Sumy Regional Center of Blood Service.

Results: It was found that total protein indicator is the normal range and albumin after plasmapheresis and during conservative treatment.

Markers of cytolysis and cholestasis are have great value may. The most significant changes were observed in rates indicating lesion of the hepatic parenchyma, including ALT, AsAT and alkaline phosphatase. In conservative treatment, the percentage of the alkaline phosphatase level improved by $31 \%$, after the course of plasmapheresis - by $58 \%$. The obtained figures of cholestasis indexes indicate the effectiveness of both methods of treatment, but treatment with plasmapheresis has a more expressed effect on the decrease of alkaline phosphatase level. The level of bilirubin improve on 38,8\% after plasmapheresis and 65\% in the comparison group.

Conclusion: Inclusion in the complex therapy of chronic hepatitis plasmapheresis reduces the severity of cytolysis and cholestasis, increases remission and significantly improves clinical manifestations.
\end{abstract}

KEY WORDS: hepatitis, plasmaferesis, remission

Wiad Lek. 2020;73(7):1454-1458

\section{INTRODUCTION}

Chronic diffuse liver diseases (CDLD) remain one of the most urgent problems of the present, as they were before, due to their widespread prevalence, pathogenetic mechanisms, which are not fully studied, unresolved problems of treatment, prevention and unfavorable prognosis. The majority of liver diseases treated by therapeutists are chronic hepatitis. This is a group of diseases caused by various reasons, characterized by focal hepatocellular necrosis of varying duration and chronic inflammation. The concept of "chronic hepatitis" is determined by the disease duration, the conditional limit is 6 months $[1,2]$. Four types of chronic hepatitis are distinguished: viral, autoimmune, drug-induced and cryptogenic. For today, hepatologists identify the fifth type of the disease as alcoholic chronic hepatitis $[3,4]$. Chronic viral hepatitis is more often caused by hepatitis B (HBV), C (HCV) and D (HDV) viruses, the last one is usually coincided with hepatitis B. High infection rate with the HBV virus of the planet's population is related to its extraordinary prevalence rate and resistance, which is 50-100 times higher than that for HIV [5]. An important place among hepatitis is drug-induced, caused by hepatotoxic drugs[6].
Medicinal liver damage is reason for approximately $2 \%$ of liver jaundices. At present, there are known more than 1,000 drugs that can cause drug-induced hepatitis. Liver lesions are more common in enteral use of drugs, due to the peculiarities of their metabolism and blood supply of hepatic tissue $[7,8]$.

Depending on the influence of the etiological factor, the synthetic activity of the liver is reduced, the detoxication function suffers and the regulation of metabolic processes is violated. The imbalance between the physiological needs and the functional capabilities of the damaged liver leads to the development of complications [9].

In this regard, the problem of finding additional therapeutic measures, including the development and introduction of new methods of pathogenetic therapy remains relevant. There are publications about the successful use of the apheresis method in modern literature. The following types of apheresis are distinguished: sorption, cypress, high-volume/massive plasma exchange (HVP), immunosorbtion (IS), apheresis LDL, plasmapheresis. Plasmapheresis is a method of efferent therapy in which the patient or donor's blood is passed through a medical device that separates the plasma from other components of the blood. Plasma is 
removed and replaced by a plasma replacement solution (for example: albumin, $\mathrm{NaCl} 0.9 \%$, donor plasma) [10]. It is important the type of solution that should be used in the process of therapeutic apheresis for a practitioner, as well as the state of the factors of blood coagulation, since there is a risk of exhaustion of coagulation factors, especially after weekly PF and the timing of the procedure. There are two main methods of automatic plasmapheresis: centrifugal and filtration. The first method is carried out by centrifugation of blood with a constant or intermittent flow of it in special devices, the other one is based on blood filtration in special plasma filters [11].

\section{THE AIM}

The aim of our research is to determine the pathogenetic expediency, efficiency and place of therapeutic plasmapheresis in the complex treatment of patients with chronic hepatitis.

Objectives of the study: 1 . To establish the validity of conservative treatment effect and treatment effect with the addition of plasmapheresis on hematological parameters after 2 weeks.

2. To determine the economic effect of the inclusion of plasmapheresis in therapy.

\section{MATERIALS AND METHODS}

The research was conducted by the Department of Public Health in the Medical Institute of Sumy State University. The analysis of the case histories was carried out on 77 patients (43 men and 34 women) aged from 15 to 75 years. In the process of treatment, patients were diagnosed with chronic toxic hepatitis (K.71). Diagnosis of patients was exhibited according to the official documentation by the implemented Gastroenterological department of Sumy Regional Clinical Hospital "SRCH", Sumy Regional Infectious Diseases Clinical Hospital named by Krasovytskyi Z.Y. and Sumy Regional Blood Service Center according to the ICD-10.

All patients were divided into two representative groups with the only conservative drug therapy $(n=39)$ and conservative treatment with therapeutic plasmapheresis $(\mathrm{n}=38)$.

A conservative therapy of hepatitis included a diet limitation of protein in the food; correction of hemostasis, hypoalbuminemia and water electrolyte state; infusion-detoxification therapy; prevention of erosive-ulcerous lesions of the gastrointestinal tract; conducting a medical therapy aimed at reducing liver encephalopathy.

In this case, a device for membrane plasmapheresis AMPA-TT (trademark "Hemofenix") was used, with the complex of a plasma filter PFM-TT "ROSA" and bloodflow lines. The process of membrane plasmapheresis on the device "Hemofenix" is carried out according to a single-needle scheme in a sterile extracorporeal contour of a single use. Vascular access was performed through peripheral subcutaneous veins (elbow vein). Average duration of the procedure is 1 -hour \pm 10 minutes. During the procedure, an average of $650 \pm 30 \mathrm{ml}$ of plasma was obtained. During the operation, the patient was given $\mathrm{NACl} 0.9 \%-200 \mathrm{ml}$, rheosorbilact - $200 \mathrm{ml}$, glucagon $-250 \mathrm{ml}$, heparin $-10 \%$ OD. In some patients instead of sorbilact/rheosorbilact were used rheopolyglucinum - 200 $\mathrm{ml}$ or refortanum $-200 \mathrm{ml}$. In total, for treatment, there were received an average of $3370 \mathrm{ml}$. of plasma (about 1 volume of circulating blood). The number of procedures for therapeutic plasmapheresis, the maximum number of performed aperitifs is eight, the minimum are 3 times at intervals between procedures for 2 days. To control the parameters of homeostasis, a complex of clinical and instrumental-laboratory methods was used. Among the clinical methods, the following parameters were assessed: general condition, skin color, blood pressure, pulse and body temperature, which were performed for all patients before, during and after the method of extracorporeal hemocorrection. Among instrumental and laboratory methods: mesenchymal inflammation (total protein, albumin), cytolysis markers (ALT, AsAT) and cholestasis (activity of alkaline phosphatase, bilirubin) were studied. Blood samples for laboratory control of the studied parameters were taken during the admission of the patient in the hospital (before treatment) during a conservative therapy and after the application of the course of therapeutic plasmapheresis.

Albumin index was determined by electrophoresis on cellulose acetate tapes.

Alanine aminotransferase (ALT) was determined by the kinetic method of the automatic analyzer Sobas C311 using the test system: AST, Roche Diagnostics.

Aspartate aminotransferase (AsAT) was determined by the kinetic method of the automatic analyzer Sobas C311 using the test system: AST, Roche Diagnostics.

Rates of alkaline phosphatase were calculated by the colorimetric method of the Sobas C311 analyzer using the test system: ALP2 Roche Diagnostics.

The level of total bilirubin was determined by the Endrassic-Klegorn-Grof method.

The study was conducted in accordance with the requirements of medical statistics, on the condition of the informed voluntary consent of patients for the processing of personal data. The resulting digital information was processed with using Microsoft Excel 2010, Statistica 10 (StatSoft Inc. USA) software using descriptive, comparative analysis.

The general statistical analysis of determining the authenticity of the difference in quantitative characteristics between the samples was used by Student's criterion. Differences were considered statistically significant at $\mathrm{p}<0.05$.

\section{RESULTS AND DISCUSSION}

According to the results of the monitoring of patients with $\mathrm{CH}$, changes in clinical and laboratory parameters were established. After analyzing 77 stories of the disease, the following distribution of patients was found: 34 (44\%) women and 43 (56\%) men. 

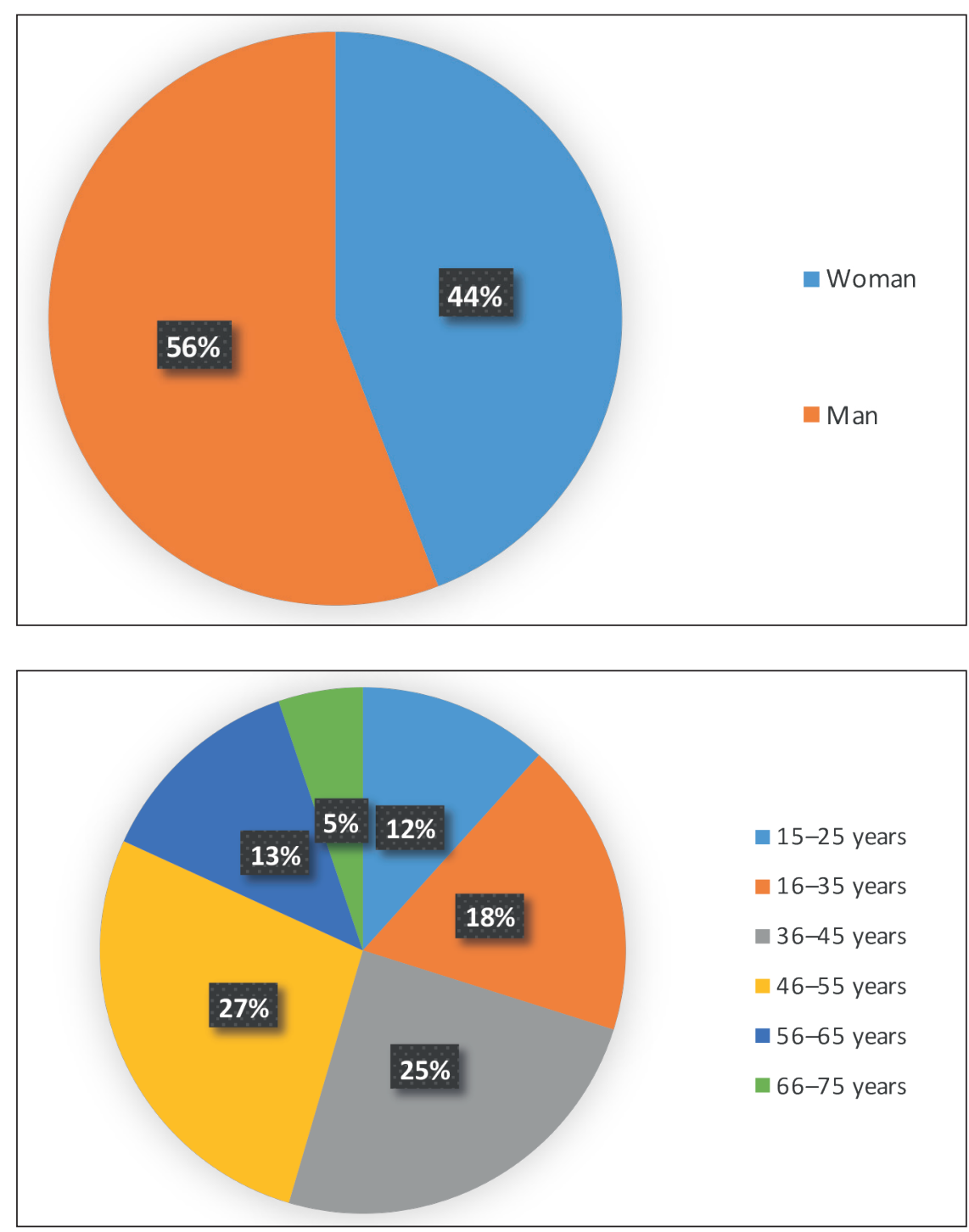

Fig 1. Sexual distribution of persons

Fig 2. Age distribution of patients
According to the age, all patients were divided into the following groups: from 15 to 25 years old - 9 (12\%), from 26 to 35 years old - 14 (18\%), from 36 to 45 years old - 19 (25\%), from 46 to 55 years old - 21 (27\%), from 56 to 65 years old - $10(13 \%)$, from 66 to 75 years old $-4(5 \%)$.

According to the results of the monitoring patients, there were diagnosed the leading clinical syndromes, the most marked were astenovegetative and dyspeptic. Also among patients were found hepatomegaly (enlargement of the liver for $6-8 \mathrm{~cm}$ ), yellowness of the skin and itchy skin. By evaluating the laboratory rates, changes in mesenchymal inflammation, markers of cytolysis and cholestasis were determined by us.

A rank evaluation of the degree of accuracy (according to the $t$-criterion) of all studied rates of homeostasis in the patients under the influence of treatment plasmapheresis and a conservative treatment showed that membrane plasmapheresis with the conservative method, had a more marked effect on homeostatic functions. These studies in groups are presented in Table I.

Analysis of the data obtained during the work showed that comparing the results of biochemical studies in classical therapy and therapy using plasmapheresis, the greatest effect was observed precisely when using plasmapheresis.

In the course of scientific work, were determined changes biochemical parameters. It was found that the level of total protein on the background of the plasmapheresis procedure (before the procedure $-73,6 \pm 5,2 \mathrm{~g} / \mathrm{l}(\mathrm{p}<0,05)$, after $-68,9 \pm 5,1 \mathrm{~g} / \mathrm{l}(\mathrm{p}<0,05))$ and during conservative treatment (before treatment initiation $-76.4 \pm 8.8 \mathrm{~g} / \mathrm{l}$ (p $<0.05)$, after treatment $-72.4 \pm 6.1 \mathrm{~g} / \mathrm{l}(\mathrm{p}<0.05))$ has not changed significantly and is within the normal range, indicating the same effect of conservative and plasmapheresis treatment on this indicator. It should be noted that in the first day was determined a significant decrease in total protein after plasmapheresis, but after 2 weeks the figure returned to normal.

Albumin after 2 weeks of treatment did not change statistically, this indicates that the effect of plasmapheresis on this indicator during the specified period is unreliable.

The most significant changes were observed in rates indicating lesion of the hepatic parenchyma, including ALT, AsAT and alkaline phosphatase. During a conservative 
Table I. Dynamics of homeostasis rates in patients with $\mathrm{CH}$ under a conservative treatment and using plasmapheresis.

\begin{tabular}{|c|c|c|c|c|}
\hline Rates & Norm & Before treatment & $\begin{array}{c}\text { After } \\
\text { treatment }\end{array}$ & $\begin{array}{l}\text { Reliability } \\
\text { of influence }\end{array}$ \\
\hline \multicolumn{5}{|c|}{ Conservative treatment } \\
\hline Total protein, g/l & $65-85$ & $76.4 \pm 8.8^{*}$ & $72.4 \pm 6.1^{*}$ & - \\
\hline Albumin, $\%$ & $36-50$ & $43.1 \pm 2.5^{*}$ & $42.9 \pm 1.0^{*}$ & - \\
\hline AsAT, O/L & $10-30$ & $90.7 \pm 20.1^{*}$ & $40.1 \pm 15.1^{*}$ & + \\
\hline $\mathrm{ALT}, \mathrm{O} / \mathrm{L}$ & $7-40$ & $76.7 \pm 20.2^{*}$ & $40.2 \pm 12.0^{*}$ & - \\
\hline Alkaline phosphatase, $\mathrm{O} / \mathrm{L}$ & $39-117$ & $152.0 \pm 19.1^{*}$ & $105.5 \pm 20.3^{*}$ & - \\
\hline Total bilirubin, $\mathrm{mcmol} / \mathrm{L}$ & $3,4-20,5$ & $67.2 \pm 10.0^{*}$ & $41.1 \pm 8.1^{*}$ & + \\
\hline \multicolumn{5}{|c|}{ Treatment with plasmapheresis } \\
\hline Total protein, g/l & $65-85$ & $73.6 \pm 5.2^{*}$ & $68.9 \pm 5.1^{*}$ & - \\
\hline Albumin, \% & $36-50$ & $45.7 \pm 2.3^{*}$ & $43.8 \pm 3.1^{*}$ & - \\
\hline AsAT, O/L & $10-30$ & $125.6 \pm 41.2^{*}$ & $37.1 \pm 14.2^{*}$ & + \\
\hline $\mathrm{ALT}, \mathrm{O} / \mathrm{L}$ & $7-40$ & $94.2 \pm 23.4^{*}$ & $38.3 \pm 15.1^{*}$ & + \\
\hline Alkaline phosphatase, $\mathrm{O} / \mathrm{L}$ & $39-117$ & $174.9 \pm 41.8^{*}$ & $73.1 \pm 27,4^{*}$ & + \\
\hline Total bilirubin, $\mathrm{mcmol} / \mathrm{L}$ & $3,4-20,5$ & $74.1 \pm 21.4^{*}$ & $25.5 \pm 8.1^{*}$ & + \\
\hline
\end{tabular}

*the indicator is considered unreliable $\mathrm{p}<0.05$

treatment, the AsAT rates were: till 90,7 $\pm 20,1 \mathrm{O} / \mathrm{L}$ against $40,1 \pm 15,1 \mathrm{O} / \mathrm{L}$, in the percentage the indicator changed by $29 \%$. During therapeutic plasmapheresis: before the procedure was $125,6 \pm 41,2 \mathrm{O} / \mathrm{L}$, against $37,1 \pm 14,2 \mathrm{O} / \mathrm{L}$, the percentage changed by $70 \%$.

Indicators of ALT to a conservative treatment were 76,7 $\pm 20,2 \mathrm{O} / \mathrm{L}$, against $40,2 \pm 12,0 \mathrm{O} / \mathrm{L}$, the normalization of the indicator is $48 \%$. In the course of therapeutic plasmapheresis: till 94,2 $\pm 23,4 \mathrm{O} / \mathrm{L}$, against $38,3 \pm 15,1 \mathrm{O} / \mathrm{L}$ the rate changed by $59 \%$. The obtained figures points out the effectiveness of both methods of treatment, but plasmapheresis has more expressed effect on the decrease of cytolysis markers.

Having evaluated the level of alkaline phosphatase in the main group and the comparison one, it was before the procedure $152.0 \pm 19.1 \mathrm{O} / \mathrm{L}$, after $105.5 \pm 20.3 \mathrm{O} / \mathrm{L}$, in contrast to the control group (before $174.9 \pm 41.8 \mathrm{O} / \mathrm{L}$, after was $73.1 \pm 27.4 \mathrm{O} / \mathrm{L}$ ). In conservative treatment, the percentage improved by $31 \%$, after the course of plasmapheresis - by $58 \%$.

Further research of cholestasis indexes points out changes in the level of total bilirubin. Normally, it is 3.4$20.5 \mathrm{mcmol} / \mathrm{L}$. There is a deviation from these normative figures in both groups. In the main group before of plasmapheresis procedures, it is $74.1 \pm 21.4 \mathrm{mcmol} / \mathrm{L}$, against $25.5 \pm 8.1 \mathrm{mcmol} / \mathrm{L}$, the index has changed by $66 \%$. In the comparison group: before is $67.2 \pm 10.0 \mathrm{mcmol} / \mathrm{L}$, after $-41.1 \pm 8.1 \mathrm{mcmol} / \mathrm{L}$, the improvement is by $39 \%$. The obtained figures indicate the effectiveness of both methods of treatment, but treatment with plasmapheresis has a more expressed effect on the decrease of alkaline phosphatase level.

\section{DISCUSSION}

The analysis of the database showed that the conservative therapy led to the improvement in the patient's condition less than after plasmapheresis. The synthetic function of the liver was recollected more slowly. The level of total protein, albumin remained within the norm in 2 weeks.

Patients in the group with therapeutic plasmapheresis were performed, showed the improvement in the general condition: faster asteno-vegetative and dyspeptic syndromes, decreasing of skin itching and intoxication symptoms. After courses of plasmapheresis at intervals of 2 days, there was a significant decrease in AsAT, ALT, AP and total bilirubin, which was maintained 2 weeks after the completion of the procedures. Due to the adequate replacement of single-group plasma losses, the patients are registered with the improvement in albumin and total protein rates, although they were also within normal parameters. Thus, complex treatment of $\mathrm{CH}$ with the inclusion of plasmapheresis has a positive effect on the disease due to the mechanical removal of toxic products from the blood of patients.

The statistical data processing demonstrates a more valid treatment effect on hematological parameters when plasmapheresis is included in the course of therapy. Conservative therapy showed statistically significant effects on AsAT and total bilirubin.

Therapy with plasmapheresis showed statistically significant effects on AsAT, ALT, alkaline phosphatase and total bilirubin. Thus, it is the greater the therapy effectiveness with the inclusion of plasmapheresis.

To study the prolonged action of plasmapheresis, we conducted an analysed repeated referrals of patients. In conservative treatment, the average interval between appeals was 18 months and 22 months after plasmapheresis therapy. 
As a result of a survey of patients who were discharged at the time of publication after an in-hospital treatment, the average cost of therapy was 42.5 euros. According to a sample retrospective study of a history of 10 years, the cost of therapy for 1 patient at treatment every 18 months ( 7 times for 10 years) is $42.5 \times 7=297.5$ euros.

The cost of the plasmapheresis procedure on Scinomed machine we have taken to calculate is 19 euros (basic fixed and variable costs, including staff salaries and utilities according Ukrainian law, are also taken into account).

The course of treatment consists of 3 procedures as minimum, which require 57 euros. For 10 years the cost of treatment with plasmapheresis for 1 patient at treatment every 22 months ( 5 times for 10 years) is $57 \mathrm{x} 5=285$ euros.

Today the cost of therapy is 297.5 euros, the economic effect during 10 years from the implementation of plasmapheresis can be estimated at 297.5-285 = 12 euros for each patient.

Therefore, the economic effect for Ukraine can be calculated as follows.

According statistics there are 104879 cases with such a pathology are officially registered in Ukraine, then the inclusion of plasmapheresis can have an economic effect for the year 12x104879 $=209758$ euros.

And considering that only $7 \%$ of the estimated number of patients is recorded, then the possible economic effect is: $12 \times 104879 \times 100 / 7$ = 2996542 euros

These data indicate the need for further more in-depth study of ways to optimize the treatment of nosologies, in which the effectiveness of plasmapheresis is proven.

\section{CONCLUSIONS}

The absence of a significant and stable effect of the conservative treatment of $\mathrm{CH}$ indicates the need to improve the quality of a medical care for patients with $\mathrm{CH}$ by using more effective up-to-date techniques, such as usage of plasmapheresis in a complex of therapeutic measures. Inclusion plasmapheresis in the complex therapy of $\mathrm{CH}$ reduces the express of cytolysis and cholestasis, increases remission and significantly improves clinical manifestations. Therefore, it is relevant to use this technique in clinical practice.

It is determined that the inclusion of therapeutic plasmapheresis in the complex therapy of hepatitis leads to an economic effect and requires further study of the impact of this method with a view to its implementation through the use of modern economic and marketing methods not only at the state level, but also in the private family medicine sector.

\section{REFERENCES}

1. Sarin S.K, Choudhury A., Sharma M.K., et al. Acute-on-chronic liver failure: consensus recommendations of the Asian Pacific association for the study of the liver (APASL): an update [published correction appears in Hepatol Int. 2019 Nov;13(6):826-828]. Hepatol Int. 2019;13(4):353390. doi:10.1007/s12072-019-09946-3

2. Korean Association for the Study of the Liver (KASL). KASL clinical practice guidelines for management of chronic hepatitis B. Clin Mol Hepatol.2019;25(2):93-159. doi:10.3350/cmh.2019.1002
3. Terrault N.A., Lok ASF, McMahon B.J, et al. Update on prevention, diagnosis, and treatment of chronic hepatitis B: AASLD 2018 hepatitis B guidance. Hepatology. 2018;67(4):1560-1599. doi:10.1002/hep.29800

4. Li, Bei et al. Nonalcoholic Fatty Liver Disease Cirrhosis: A Review of Its Epidemiology, Risk Factors, Clinical Presentation, Diagnosis, Management, and Prognosis. Can J Gastroenterol Hepatol. vol. 2018. doi:10.1155/2018/2784537

5. Inoue, Takako, and Yasuhito Tanaka. Hepatitis B virus and its sexually transmitted infection - an update. Microbial cell.2016:3(9): 420-437. doi:10.15698/mic2016.09.527

6. Murtuzaglya A., Golubovskaya 0.A., Buggish P. at al. Expanding the possibilities of treatment for hepatitis C. Health of Ukraine. 2017;3:14-15.

7. Yew, Wing Wai et al. Oxidative Stress and First-Line Antituberculosis Drug-Induced Hepatotoxicity. Antimicrobial agents and chemotherapy. 2018;62(8):e02637-17. doi:10.112/AAC.02637-17

8. Deavall D.G., Martin E.A., Horner J.M., et at. Drug-induced oxidative stress and toxicity. J Toxicol 2012:645460. doi:10.1155/2012/645460.

9. Mauss S, Pol S, Buti M, et al. Late presentation of chronic viral hepatitis for medical care: a consensus definition. BMC Med. 2017;15(1):92. doi:10.1186/s12916-017-0856-y

10. Schwartz J., Padmanabhan A., Akvy N., et al. Recommendations on the application of therapeutic apheresis in clinical practice-the evidentiary approach of the American community-based editorial committee for afaresis: seventh special edition. Part 1. American Society for Apheresis (ASFA) Journal of Clinical Apheresis.2016:31:149-338.

11. Timchenko A.S, Smiyanov V.A., Lyubchak V.P., et al. Terminology of procedures for blood sampling and obtaining its components. Medicinal business.2015:5(6):140-143.

\section{ORCID and contributionship}

Vladislav V. Lyubchak - 0000-0003-0352-4355 A,B,D,E

Viktoriia M. Plaksa - 0000-0002-1627-1492 A,B,D,E

Ihor M. Pelo - 0000-0002-4764-102X ${ }^{E, F}$

Michael P. Kovalishyn - 0000-0002-7120-0304 A,B,D,E

Vladimir V. Horokh - 0000-0002-7595-7398 B,E

Viktor P. Lyubchak - 0000-0002-0615-1622 ${ }^{B, E}$

Tatyana Lisovenko Iu - 0000-0001-9035-7377 A,B,E

Viktoriia Ilyina $V$ - 0000-0002-3972-4327 B,E

Liliya M. Khomenko - 0000-0001-5690-1105 A,C,E

\section{Conflict of interest:}

The Authors declare no conflict of interest.

\section{CORRESPONDING AUTHOR \\ Vladislav V. Lyubchak}

Medical Institute, Sumy State University

1 Sanatorna str, 40018 Sumy, Ukraine

tel: +380958000333

e-mal: ur3abm@i.ua

Received: 20.11.2019

Accepted: 27.05 .2020

A - Work concept and design, B - Data collection and analysis, C - Responsibility for statistical analysis,

D-Writing the article, $\mathbf{E}$-Critical review, $\mathbf{F}$ - Final approval of the article 